\title{
多成分混合物における配位数サンプリングによる 接触数混合度の推定
}

\author{
Estimation of Mixing Index Based on Contact Numbers by \\ Coordination Number Sampling from a Multicomponent Mixture
}

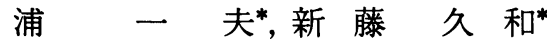 \\ Kazuo URA*, Hisakazu SHINDO*
}

\begin{abstract}
A mixing index based on contact numbers by coordination number sampling was proposed by Akao et al. The contact number is defined as the number of particles which are in contact with a particular particle called a specified particle. Statistically, the contact number mixing index is on the basis of the first moment, mean, in contrast to variance-based indexes such as Lacey's.

Shindo reported the distribution of contact numbers from a binary mixture in an incompletely mixed state. The distribution was derived from a beta-binomial distribution as a conditional one.

This paper extends the distribution of contact numbers for a binary case to that for a multicomponent case. The precison of estimation of the mixing index is theoretically derived and compared with that of reduced binary case. It can be concluded that the best precision is obtained if we select the particles whose population concentration is lowest as specified particles. This conclusion holds whatever the number of components is.
\end{abstract}

Key Words : Multicomponent Mixing, Mixing Index, Coordination Number Sampling, Dirichlet-multinomial Distribution, Contact Number

\section{1. 緒言}

固体粒子混合における代表的な統計的混合度として は, Lacey ${ }^{1)}$ の分散による混合度が知られている。こ れは，着目成分粒子のサンプル間の分散に基づいて混 合度を表示するものである。しかし，着目成分粒子の 母集団分布が知られていないため，この定義では標本 分散を用いている。

赤尾ら ${ }^{2)}$ は, 分散は統計的には重要な概念であるが, 巨視的であり物理的な意義が不明確であるとして，接 触数による混合度の表示法を提案した。接触数は，指 定成分粒子と呼ばれる特定の成分粒子に接触する着目 成分粒子の数として定義されている。また，この定義 に即して行われるサンプリング法は配位数サンプリン

\section{5年 8月 18日受付}

* 山梨大学工学部軋子情報工学科

(テ400 甲付市武田 4-3-11)TEL. 0552-20-8499

Fac. of Eng., Dept. of Electrical Eng. and Computer

Sci., Yamanashi Univ.

(4-3-11 Takeda, Kofu-shi, 400)
グと呼ばれる。分散が統計的には2次モーメントであ るのに対し，接触数は1次モーメントであるところに 特徴がある。

その後, 吉澤・新藤 ${ }^{3)}$ は, 2 成分からなる固体粒子群 の混合状態を記述するベータ二項分布に基づくモデル を提案し, Lacey ${ }^{1)}$ の混合度の推定精度を報告してい る。また，このモデルを多成分混合に拡張したディリ クレ多項分布を用いて, Too, et al. ${ }^{4}$ は, 多成分混合 におけるスポットサンプリングによる接触数混合度の 推定精度を検討している。

最近, 新藤 ${ }^{5)}$ は, 2 成分混合のベータ二項モデルから 配位数サンプリングによる接触数の分布を導き，接触 数とそれによる混合度の推定精度を報告した。

本報告では，多成分混合物における配位数サンプリ ングによる接触数の分布を導き, 接触数混合度の理論 推定精度を求め, コンピュータ・シミュレーションに よりその妥当性を検討する。さらに, 多成分混合物の 接触数混合度の推定精度と多成分混合物をある成分と 残りの成分とからなる 2 成分混合物とみなしたときの 
接触数混合度の推定精度とを比較する。

\section{2. 多成分混合物における接触数と艺の分布}

\section{1 接触数の定举}

いま, $(s+1)$ 種類の同径粒子群からなる二次元規則 配列混合物を考える。ここで, $A_{\mathrm{j}}(\mathrm{j}=0,1,2, \cdots, \mathrm{s})$ 粒 子の母個数䈨度をそれぞれ $\bar{X}_{\mathrm{j}}$ とすれば, それらの総和 は1となる。

この混合物からランダムに取り出された粒子を抽出 粒子といい, この粒子に接しているすべての粒子の数 を総配位数 $n^{*}$ という。総配位数 $n^{*}$ は混合物の配列構造 により定まり，正方配列と六方配列のそれぞれに対し て $n^{*}=4$ および $n^{*}=6$ となる。抽出粒子を $A_{0}$ 粒子に限定 することを， $A_{0}$ 粒子を指定粒子とするといい，指定粒 子 $A_{0}$ に接する $A_{\mathrm{j}}$ 粒子の数を第 $\mathrm{j}$ 成分の接触数と定義す る(Fig. 1参照)。大きさ $n^{*}$ の配位数サンプリングによ り得られる第 $\mathrm{j}$ 成分の接触数を表す確率変数を $C_{\mathrm{j}(0)}$, その実現值を $c_{\mathrm{j}(0)}$ とする。次節以降でこの接触数 $C_{\mathrm{j}(0)}$ の分布について, 2 成分混合物の場合 ${ }^{5}$ に对応させて 検討する。

\section{2 完全分離状態}

$(s+1)$ 種類の粒子がそれぞれ $(s+1)$ 層に分離してい る状態を完全分離状態という。この状態では, 混合物 を無限母集団とし，境界を無視すれば，抽出粒子は $A_{0}$ 層にのみ限定され，しかも $A_{0}$ 首における $A_{\mathrm{j}}(\mathrm{j}=1,2$, $\cdots, s)$ 粒子は存在しない。したがって, 接触数 $C_{\mathrm{j}(0)}$ は 常に0となるから次式の一点分布に従う。

$$
\begin{aligned}
& \operatorname{Pr}\left[C_{1(0)}=c_{1(0)}, \cdots, C_{\mathrm{s}(0)}=c_{\mathrm{s}(0)}\right] \\
& \quad=\operatorname{Pr}\left[\left\{C_{\mathrm{j}(0)}\right\}=\left\{c_{\mathrm{j}(0)}\right\}\right]=\left\{\begin{array}{l}
1\left(c_{\mathrm{j}(0)}=0\right) \\
0(\text { otherwise })
\end{array}\right.
\end{aligned}
$$

この分布Eq. (1)における接触数 $C_{\mathrm{j}(0)}$ の期待値 $\mu_{\mathrm{sj}}$ と分 散 $\sigma_{\mathrm{sj}}{ }^{2}$ はそれぞれ次式で与えられる。

$$
\begin{aligned}
& \mu_{\mathrm{sj}}=E\left(C_{\mathrm{j}(0)}\right)=0 \\
& \sigma_{\mathrm{sj}}{ }^{2}=V\left(C_{\mathrm{j}(0)}\right)=0
\end{aligned}
$$



Fig. 1 Illustration of a coordination number sample of size $n^{*}=6$

\section{3 完全混合状態}

$(s+1)$ 種類の粒子が統計的に全くランダムに配置し ている状態を完全混合状態という。この状態から大き さ $n^{*}$ の配位数サンプリングを行うと, $n^{*}$ 個の粒子中に は $A_{0}, A_{1}, \cdots, A_{\mathrm{s}}$ 粒子が全くランダムな割合で含まれ ているはずである。したがって,この状態では接触数 $C_{\mathrm{j}(0)}$ は次の多項分布に従う。

$$
\begin{aligned}
& \operatorname{Pr}\left[\left\{C_{\mathrm{j}(0)}\right\}=\left\{c_{\mathrm{j}(0)}\right\}\right] \\
& \quad=\left(\begin{array}{c}
n^{*} \\
c_{1(0)} \cdots c_{\mathrm{s}(0)}
\end{array}\right) \bar{X}_{1}{ }^{c(10)} \cdots \bar{X}_{\mathrm{s}}^{c_{\mathrm{s}(0)}} \bar{X}_{0}^{\mathrm{n}^{*}-\sum_{j=1}^{s} c_{(0)}}
\end{aligned}
$$

この分布 Eq. (4)における接触数 $C_{\mathrm{j}(0)}$ の期待值 $\mu_{\mathrm{r} j}$ と分 散 $\sigma_{\mathrm{rj}}{ }^{2}$ はそれぞれ次式のようになる。

$$
\begin{aligned}
& \mu_{\mathrm{rj}}=E\left(C_{\mathrm{j}(0)}\right)=n^{*} \bar{X}_{\mathrm{j}} \\
& \sigma_{\mathrm{rj}}{ }^{2}=V\left(C_{\mathrm{j}(0)}\right)=n^{*} \bar{X}_{\mathrm{j}}\left(1+\bar{X}_{\mathrm{j}}\right)
\end{aligned}
$$

また, 接触数 $C_{\mathrm{i}(0)}$ と $C_{\mathrm{j}(0)}$ との共分散 $\operatorname{Cov}\left(C_{\mathrm{i}(0),}, C_{\mathrm{j}(0)}\right)$ $(\mathrm{i} \neq \mathrm{j})$ は次式で与えられる。

$$
\operatorname{Cov}\left(C_{\mathrm{i}(0)}, C_{\mathrm{j}(0)}\right)=-n^{*} \bar{X}_{\mathrm{i}} \bar{X}_{\mathrm{j}}
$$

\section{4 不完全混合状態}

不完全混合状態は, 完全分離状態から完全混合状態 に至る中間の状態である。この状態では，それぞれの 成分粒子の局所的洪度のムラが大きくなり, 混合物全 体からみても一様とは考えられず, 局所的湌度それ自 体がある分布に従う確率変数であると考えるのが自然 である。そこで, 第 $\mathrm{j}$ 成分の局所的鈛度を表す確率変 数を $p_{\mathrm{j}}$ とし，その確率密度関数 $f$ を次式のディリクレ 密度とする。

$$
f\left(p_{0}, \cdots p_{\mathrm{s}}\right)=\frac{\Gamma(\tau)}{\prod_{\mathrm{j}=0}^{s} \Gamma\left(\tau \overline{X_{\mathrm{j}}}\right)} \prod_{j=0}^{\mathrm{s}} p_{\mathrm{j}}^{\tau \overline{\mathrm{X}}_{\mathrm{j}}-1}
$$

$$
\text { ここで, } て \text { は正のパラメータ, }(\text { ) はガンマ関数で }
$$
ある。

局所的浱度 $\left\{p_{\mathrm{j}}\right\}$ が与えられたという条件のもとで, 抽出粒子が $A_{0}$ であり，かつその周囲の $n^{*}$ 個の粒子のう ち $y_{\mathrm{j}}$ 個が $A_{\mathrm{j}}$ 粒子である確率は， $y_{\mathrm{j}}$ に対する確率変数を $Y_{\mathrm{j}}$ として,

$$
\begin{aligned}
& \operatorname{Pr}\left[\left\{Y_{\mathrm{j}}\right\}=\left\{y_{\mathrm{j}}\right\}, \quad A_{0} \mid\left\{p_{\mathrm{j}}\right\}\right] \\
& \quad=\left(\begin{array}{c}
n^{*} \\
y_{1} \cdots y_{\mathrm{s}}
\end{array}\right) \bar{X}_{0}^{n^{*}-\sum_{j=1}^{s} y_{j}+1} \prod_{j=1}^{\mathrm{s}} \bar{X}_{\mathrm{j}}^{\text {h }}
\end{aligned}
$$

となるから, $\operatorname{Pr}\left[\left\{Y_{\mathrm{j}}\right\}=\left\{y_{\mathrm{j}}\right\}, A_{0}\right]$ は, Eqs. (8) と(9)の同 時確率の周辺確率として次のように表される。 


$$
\begin{aligned}
& \operatorname{Pr}\left[\left\{Y_{\mathrm{j}}\right\}=\left\{y_{\mathrm{i}}\right\}, A_{0}\right] \\
& =\int \cdots \int_{D} \operatorname{Pr}\left[\left\{Y_{\mathrm{j}}\right\}=\left\{y_{\mathrm{j}}\right\}, A_{0} \mid\left\{p_{\mathrm{j}}\right\}\right] \\
& \text { - } f\left(p_{0}, p_{1}, \cdots, p_{\mathrm{s}}\right) \mathrm{d} p_{1} \cdots \mathrm{d} p_{\mathrm{s}}
\end{aligned}
$$

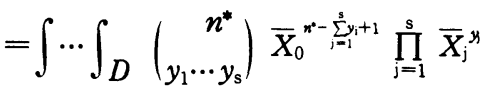

$$
\begin{aligned}
& \cdot \frac{\Gamma(\tau)}{\prod_{j=0}^{s} \tau \bar{X}_{\mathrm{j}}} \prod_{j=0}^{s} p_{\mathrm{j}}^{\mathrm{t} \bar{X}^{-1}} \mathrm{~d} p_{1} \cdots \mathrm{d} p_{\mathrm{s}}
\end{aligned}
$$

ここで, $D: p_{0} \geqq 0, \cdots, p_{\mathrm{s}} \geqq 0 ; p_{0}+\cdots+p_{\mathrm{s}}=1$ であ る。これより，抽出粒子が $A_{0}$ 粒子であるという条件の もとで，その周囲に $y_{j}$ 個の $A_{j}$ 粒子があるという確率は 次式のようになる。

$$
\operatorname{Pr}\left[\left\{Y_{\mathrm{j}}\right\}=\left\{y_{\mathrm{j}}\right\} \mid A_{0}\right]=\operatorname{Pr}\left[\left\{Y_{\mathrm{j}}\right\}=\left\{y_{\mathrm{j}}\right\}, A_{0}\right] / \operatorname{Pr}\left[\mathrm{A}_{0}\right]
$$

$$
\begin{aligned}
& =\frac{1}{\bar{X}_{0}} \int \cdots \int_{D}\left(\begin{array}{c}
n^{*} \\
y_{1} \cdots y_{\mathrm{s}}
\end{array}\right) \bar{X}_{0}^{n^{-}-\sum_{j=1}^{s} y_{i}+1} \prod_{j=1}^{\mathrm{s}} \bar{X}_{\mathrm{j}}^{y_{j}} \\
& \cdot \frac{\Gamma(\tau)}{\prod_{j=0}^{s} \tau \bar{X}_{\mathrm{j}}} \prod_{j=0}^{\mathrm{s}} p_{\mathrm{j}}^{\tau \bar{X}_{\mathrm{j}}-1} \mathrm{~d} p_{1} \cdots \mathrm{d} p_{\mathrm{s}} \\
& =\frac{1}{\bar{X}_{0}} \cdot \frac{n^{*} ! \Gamma(\tau) \Gamma\left(n^{*}-\sum_{j=1}^{s} y_{j}+\tau \bar{X}_{0}+1\right)}{\left(n^{*}-\sum_{j=1}^{s}\right) ! \Gamma\left(\tau \overline{\mathrm{X}}_{0}\right) \Gamma\left(n^{*}+\tau+1\right)} \\
& \cdot \prod_{j=1}^{s} \frac{\Gamma\left(y_{j}+\tau \bar{X}_{j}\right)}{y_{i} ! \Gamma\left(\tau \bar{X}_{j}\right)}
\end{aligned}
$$

ところで, 条件付き確率 $\operatorname{Pr}\left[\left\{Y_{\mathrm{j}}\right\}=\left\{y_{\mathrm{j}}\right\} \mid A_{0}\right]$ は接触数 の確率 $\operatorname{Pr}\left[\left\{C_{\mathrm{j}(0)}\right\}=\left\{c_{\mathrm{j}(0)}\right\}\right]$ であるから, Eq. (11) は不完 全混合状態における接触数の分布式を表していること がわかる。

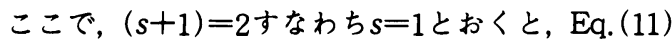
は次式の 2 成分混合物における接触数の分布式 5 )

$$
\begin{aligned}
\operatorname{Pr}[Y & \left.=y \mid A_{0}\right] \\
& =\frac{1}{\bar{X}_{0}}\left(\begin{array}{c}
n^{*} \\
y
\end{array}\right) \frac{B\left(y+\tau \bar{X}_{1}, n^{*}-y+\tau \bar{X}_{0}+1\right.}{B\left(\tau \bar{X}_{1}, \tau \bar{X}_{0}\right)}
\end{aligned}
$$

に帰着することが確かめられる。

つぎに, 不完全混合状態における接触数 $C_{\mathrm{j}(0)}$ の期待 值 $E\left(C_{\mathrm{j}}(0)\right)=\mu_{\mathrm{j}}$ と分散 $V\left(C_{\mathrm{j}(0)}\right)=\sigma_{\mathrm{j}}{ }^{2}$ を求めるため接触 数の分布Eq. (11)の階乗モーメントを求めると,

$$
\begin{aligned}
\mu_{\left(\mathrm{r} 0 \cdots \mathrm{r}_{\mathrm{s}}\right)}= & n^{*(r)} \frac{\left(r_{0}+\tau \bar{X}_{0}\right)\left(r_{0}+\tau \bar{X}_{0}-1\right) \cdots\left(\tau \bar{X}_{0}+1\right)}{(\tau+r)(\tau+r-1) \cdots(\tau+1)} \\
& \cdot \sum_{\mathrm{j}=1}^{\mathrm{s}}\left(r_{\mathrm{j}}+\tau \bar{X}_{\mathrm{j}}-1\right)\left(r_{\mathrm{j}}+\tau \bar{X}_{\mathrm{j}}-2\right) \cdots\left(\tau \bar{X}_{\mathrm{j}}\right)
\end{aligned}
$$

となる。ここで,

$$
\begin{aligned}
& n^{*(r)}=n^{*}\left(n^{*}-1\right) \cdots\left(n^{*}-r+1\right) \\
& r=r_{0}+r_{1}+\cdots+r_{\mathrm{s}}
\end{aligned}
$$

である。

この階乗モーメントEq. (13)より, 不完全混合状態 における接触数 $C_{\mathrm{j}(0)}$ の期待值 $\mu_{\mathrm{j}}$ と分散 $\sigma_{\mathrm{j}}{ }^{2}$, および接触 数 $C_{\mathrm{i}(0)}$ と $C_{\mathrm{j}(0)}$ との共分散 $\operatorname{Cov}\left(C_{\mathrm{i}(0)}, C_{\mathrm{j}(0)}\right)(\mathrm{i} \neq \mathrm{j})$ はそれぞ れ次のように求められる。

$$
\begin{aligned}
\mu_{\mathrm{j}}= & \mu(0, \cdots, 1,0, \cdots, 0)=\frac{\tau}{\tau+1} \cdot n^{*} \bar{X}_{\mathrm{j}} \\
\sigma_{\mathrm{j}}{ }^{2}= & \mu_{(0, \cdots, 2,0, \cdots, 0)}+\mu(0, \cdots 0,1,0, \cdots, 0) \\
& -\mu^{2}(0, \cdots, 0,1,0, \cdots, 0) \\
= & \frac{\tau}{\tau+1} \cdot n^{*} \bar{X}_{\mathrm{j}}\left(1-\frac{\tau}{\tau+1} \cdot \bar{X}_{\mathrm{j}}\right) \frac{\tau+1+n^{*}}{\tau+2}
\end{aligned}
$$

$$
\begin{aligned}
& \operatorname{Cov}\left(C_{\mathrm{i}(0)}, C_{\mathrm{j}(0)}\right)=\mu_{(0, \cdots, 0,1,1,0, \cdots, 0)} \\
& -\mu_{(0, \cdots, 0,1,0,0, \cdots, 0)} \cdot \mu_{(0, \cdots, 0,0,1,0, \cdots, 0)} \\
& =-\frac{\tau n^{*} \bar{X}_{\mathrm{i}} \bar{X}_{\mathrm{j}}\left(\tau+1+n^{*}\right)}{(\tau+1)^{2}(\tau+2)}
\end{aligned}
$$

ここで,これらの期待値と分散および共分散につい て，パラメータてを0とめとにそれぞれ近づけたとき の極限值は以下のようになる。

$$
\begin{aligned}
& \lim _{\tau \rightarrow 0} \mu_{\mathrm{j}}=0=\mu_{\mathrm{sj}} \\
& \lim _{\tau \rightarrow 0} \sigma_{\mathrm{j}}{ }^{2}=0=\sigma_{\mathrm{sj}}{ }^{2} \\
& \lim _{\tau \rightarrow 0} \mu_{\mathrm{j}}=n^{*} \bar{X}_{\mathrm{j}}=\mu_{\mathrm{rj}} \\
& \lim _{\tau \rightarrow 0} \sigma_{\mathrm{j}}{ }^{2}=n^{*} \bar{X}_{\mathrm{j}}\left(1-\bar{X}_{\mathrm{j}}\right)=\sigma_{\mathrm{rj}}{ }^{2} \\
& \lim _{\tau \rightarrow 0} \operatorname{Cov}\left(C_{\mathrm{i}(0)}, C_{\mathrm{j}(0)}\right)=-n^{*} \bar{X}_{\mathrm{i}} \bar{X}_{\mathrm{j}}
\end{aligned}
$$

このことは, パラメータてが0からめまで変化した とき, 接触数 $C_{j(0)}$ の分布が完全分離状態の一点分布 Eq. (1) から完全混合状態の多項分布Eq. (4)へ移行し ていることを表している。

\section{5 混合度の表示}

完全分離状態と完全混合状態におけるそれぞれの接 触数の期待值Eqs. (2) と (5)および不完全混合状態に おける期待値Eq. (14)の変化に着目して，接触数によ る混合度 $M$ を次のように定義できる4)。

$$
M=\sum_{j=1}^{\mathrm{s}} \frac{\mu_{\mathrm{j}}-\mu_{\mathrm{sj}}}{\mu_{\mathrm{rj}}-\mu_{\mathrm{sj}}} \cdot \frac{\overline{X_{\mathrm{j}}}}{1-\bar{X}_{0}}
$$

この定義式に, Eq.(2)の $\mu_{\mathrm{sj}}$ とEq. (5)の $\mu_{\mathrm{r} j}$, およびEq. 
（14）の $\mu_{\mathrm{j}}$ を代入すると,

$$
M=\frac{\tau}{\tau+1}
$$

となり，混合度がただ一つのパラメータてで表せるこ とがわかる。完全分離状態と完全混合状態に对して,

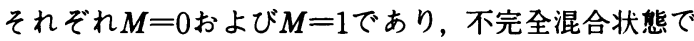
は0<M<1となる。

\section{3. 混合度の推定と光の推定精度}

\section{1 接触数の推定量と艺の推定精度}

ここでは, $(s+1)$ 種類の成分からなる混合物から大 きさ $n^{*}$ の配位数サンプルを $k$ 組抽出して, 混合度を推 定する問題を考える。混合問題においては母個数湦度 $\bar{X}_{j}$ は供給時に与えられることが多いので既知とす る。

接触数は $k$ 組の配位数サンプルの平均として次式で 推定するものとする。

$$
\widehat{c}_{\mathrm{j}(0)}=\frac{\sum_{\mathrm{i=1}}^{\mathrm{k}} c_{\mathrm{j}(0) \mathrm{i}}}{k}
$$

これより，不完全混合状態における推定量 $\widehat{c}_{\mathrm{j}(0)}$ の期 待値 $E\left(\widehat{c}_{\mathrm{j}(0)}\right)$ と分散 $V\left(\widehat{c}_{\mathrm{j}(0)}\right)$ は, Eqs. (14)および $(15)$ か らそれぞれ以下のように求められる。

$E\left(\widehat{c}_{\mathrm{j}(0)}\right)=\frac{\tau}{\tau+1} n^{*} \bar{X}_{\mathrm{j}}$

$V\left(\widehat{c}_{\mathrm{j}(0)}\right)=\frac{1}{k} \frac{\tau}{\tau+1} n^{*} \bar{X}_{\mathrm{j}}\left(1-\frac{\tau}{\tau+1} \bar{X}_{\mathrm{j}}\right) \frac{\tau+1+n^{*}}{\tau+2}$

ここで, Eqs. (14) と (25)を比較すると, 推定量 $\widehat{c}_{\mathrm{j}(0)}$ は不偏推定量であることが分かる。

以上より, 不完全混合状態における接触数の推定量 $\widehat{c}_{j(0)}$ の相対標準誤差 $R S E\left(\widehat{c}_{j(0)}\right)$ は次のように求められ る。

$$
\begin{gathered}
\operatorname{RSE}\left(\widehat{c}_{\mathrm{j}(0)}\right)=\frac{\sqrt{V\left(\widehat{c}_{\mathrm{j}(0)}\right)}}{E\left(\widehat{c}_{\mathrm{j}(0)}\right)} \\
=\left[\frac{\left(\tau+1-\tau \overline{X_{\mathrm{j}}}\right)\left(\tau+1+n^{*}\right)}{k n^{*} \bar{X}_{\mathrm{j}} \tau(\tau+2)}\right]^{1 / 2}
\end{gathered}
$$

同様にして, 接触数の推定量 $\widehat{c}_{\mathrm{j}(0)}$ の完全混合状態に おける期待値と分散および相对標準誤差はそれぞれ以 下のように求められる。

$$
\begin{aligned}
& E\left(\widehat{c}_{\mathrm{j}(0)}\right)=n^{*} \bar{X}_{\mathrm{j}} \\
& V\left(\widehat{c}_{\mathrm{j}(0)}\right)=\frac{1}{k} n^{*} \bar{X}_{\mathrm{j}}\left(1-\bar{X}_{\mathrm{j}}\right) \\
& R S E\left(\widehat{c}_{\mathrm{j}(0)}\right)=\left[\frac{1-\bar{X}_{\mathrm{j}}}{k n^{*} \bar{X}_{\mathrm{j}}}\right]^{1 / 2}
\end{aligned}
$$

ところで, 接触数の推定量 $\widehat{c}_{\mathrm{j}(0)}$ の不完全混合状態に おける期待值Eq. (25) と分散Eq. (26)においてパラメ 一夕てをめとすると, それぞれ接触数推定量 $\widehat{c}_{\mathrm{j}(0)}$ の完 全混合状態における期待值Eq. (28)および分散Eq. (29)となることがわかる。

また, 完全分離状態の場合は $E\left(\widehat{c}_{\mathrm{j}(0)}\right)=0$ となるので 相対標準誤差は定義しない。

\section{2 混合度の推定鱼と艺の推定精度}

混合度の定義Eq. (22) に完全分離状態と完全混合状 態におけるそれぞれの期待值Eqs. (2)および(5)を代 入すると

$$
M=\sum_{j=1}^{s} \frac{\mu_{j}}{n^{*}\left(1-\overline{X_{0}}\right)}
$$

となるので， $\mu_{\mathrm{j}}$ を $\widehat{c}_{\mathrm{j}(0)}$ で推定して代入することにより 混合度の推定量 $\widehat{M} と し て$ 次式が得られる。

$$
\widehat{M}=\sum_{j=1}^{\mathrm{s}} \frac{\widehat{c}_{\mathrm{j}(0)}}{n^{*}\left(1-\overline{X_{0}}\right)}
$$

これより，混合度の推定量众の不完全混合状態にお ける期待值 $E(\widehat{M})$ と分散 $V(\widehat{M})$ は, Eqs. (25) と (26) から それぞれ次式のように求められる。

$$
E(\widehat{M})=\frac{\tau}{\tau+1}
$$

$V(\widehat{M})$

$=\frac{1}{n^{*}\left(1-\bar{X}_{0}\right)^{2}}\left\{\sum_{j=1}^{\mathrm{s}} V\left(\widehat{c}_{j}(0)\right)+2 \sum_{j=1}^{\mathrm{s}} \sum_{\mathrm{k}=\mathrm{j}+1}^{\mathrm{s}} \operatorname{Cov}\left(\widehat{c}_{j}(0), \hat{c}_{\mathrm{k}}(0)\right)\right\}$

$=\frac{1}{k n^{*}\left(1-\bar{X}_{0}\right)^{2}} \frac{\tau\left(\tau+1+n^{*}\right)}{(\tau+1)(\tau+2)}$

$$
\cdot\left\{\sum_{j=1}^{s} \bar{X}_{j}\left(1-\frac{\tau}{\tau+1} \bar{X}_{\mathrm{j}}\right)-2 \sum_{\mathrm{j}=1}^{\mathrm{s}} \sum_{\mathrm{k}=1+1}^{\mathrm{s}} \frac{\tau}{\tau+1} \bar{X}_{\mathrm{j}} \bar{X}_{\mathrm{k}}\right\}
$$

したがって，相对標準誤差 $R S E(\widehat{M})$ は次式のようにな る。

$$
\begin{aligned}
\operatorname{RSE}(\widehat{M}) & =\frac{\sqrt{V(M})}{E(\hat{M})} \\
= & {\left[\frac{(\tau+1)\left(\tau+1+n^{*}\right)}{k \tau(\tau+2) n^{*}\left(1-\overline{X_{0}}\right)^{2}}\right.}
\end{aligned}
$$




$$
\begin{aligned}
& \left.\cdot\left\{\sum_{j=1}^{\mathrm{s}} \bar{X}_{\mathrm{j}}\left(1-\frac{\tau}{\tau+1} \bar{X}_{\mathrm{j}}\right)-2 \sum_{=1}^{\mathrm{s}} \sum_{\mathrm{k}=\mathrm{s}+1}^{\mathrm{s}} \frac{\tau+1}{\tau+1} \bar{X}_{\mathrm{j}} \bar{X}_{\mathrm{k}}\right\}\right]^{1 / 2} \\
& =\left[\frac{(\tau+1)\left(\tau+1+n^{*}\right)}{k \tau(\tau+2) n^{*}\left(1-\bar{X}_{0}\right)}\left\{1-\frac{\tau}{\tau+1}\left(1-\bar{X}_{0}\right)\right\}\right]^{1 / 2}
\end{aligned}
$$

同様にして, 完全混合状態の場合の混合度推定量 $\widehat{M}$ の期待値と分散および相対標準誤差はそれぞれ以下の ように求められる。

$$
\begin{aligned}
& E(\widehat{M})=1 \\
& V(\widehat{M})=\frac{1}{k n^{*}\left(1-\bar{X}_{0}\right)^{2}}\left\{\sum_{j=1}^{\mathrm{s}} \bar{X}_{\mathrm{j}}\left(1-\bar{X}_{\mathrm{j}}\right)-2 \sum_{\mathrm{j}=1}^{\mathrm{s}} \sum_{\mathrm{k}=1+1}^{\mathrm{s}} \bar{X}_{\mathrm{j}} \bar{X}_{\mathrm{k}}\right\} \\
& \quad=\left[\frac{1}{k n^{*}\left(1-\bar{X}_{0}\right)^{2}}\left\{\sum_{\mathrm{j}=1}^{\mathrm{s}} \bar{X}_{\mathrm{j}}\left(1-\bar{X}_{\mathrm{j}}\right)-2 \sum_{\mathrm{j}=1}^{\mathrm{s}} \sum_{\mathrm{k}=\mathrm{j}+1}^{\mathrm{s}} \bar{X}_{\mathrm{j}} \bar{X}_{\mathrm{k}}\right\}\right]^{1 / 2} \\
& =\left[\frac{\sqrt{V(\hat{M})}}{k n^{*}\left(1-\bar{X}_{0}\right)}\right]^{1 / 2}
\end{aligned}
$$

\section{4. コンピュータ・シミュレーションと考察}

\section{1 シミュレーションの方法}

相対標準誤差の理論式Eqs. (35)および(38)の妥当 性を検討するため,コンピュータ・シミュレーション を行った。接触数の分布Eq. (11)に従う乱数を, Polyaの壷の問題6) 利用して発生させた。シミュレ ーションは以下の手順で行った。

（1）混合度 $M$, 成分粒子の種類の数 $s$, 総配位数 $n^{*}$, 各母個数㴤度 $\bar{X}_{\mathrm{j}}$ を決める。

（2）サンプル数 $k$ を適当に与える。

(3)（4）（5）をN回繰り返す。

（4）接触数乱数を発生させ, 第 $\mathrm{i}(\mathrm{i}=1,2, \cdots, \mathrm{k})$ 市 ンプルの第 $\mathrm{j}(\mathrm{j}=1,2, \cdots, \mathrm{s})$ 成分の接触数を $c_{\mathrm{j}(0) \mathrm{i}}$ とする。第 $\mathrm{r}(\mathrm{r}=1,2, \cdots, N)$ 回目の混合度推 定量 $\widehat{M}_{\mathrm{ri}}$ を次式で計算する。

$$
\widehat{M}_{\mathrm{ri}}=\sum_{j=1}^{\mathrm{s}} \frac{c_{\mathrm{j}(0) \mathrm{i}}}{n^{*}\left(1-X_{0}\right)}
$$

（5）平均混合度 $\widehat{M}_{\mathrm{r}}$ を次式で推定する。

$$
\widehat{M}_{\mathrm{r}}=\sum_{i=1}^{\mathrm{k}} \frac{M_{\mathrm{ri}}}{k}
$$

（6）平均混合度の平均 $\bar{M}$ と標準誤差 $\widehat{D}(\widehat{M})$ をそれぞ れ次式で計算する。

$$
\begin{aligned}
& \overline{\widehat{M}}=\sum_{\mathrm{r}=1}^{\mathrm{N}} \frac{\widehat{M}_{\mathrm{r}}}{N} \\
& \widehat{D}(\widehat{M})=\left\{\sum_{\mathrm{r}=1}^{\mathrm{N}} \frac{\left(\widehat{M}_{\mathrm{r}}-\overline{\widehat{M}}\right)^{2}}{N-1}\right\}^{1 / 2}
\end{aligned}
$$

（7）相对標準誤差 $R S E(\widehat{M}) を \widehat{D}(\widehat{M}) / \widehat{M} て ゙$ 推定する。

\section{2 シミュレーション結果}

総配位数を $n^{*}=4$, それぞれの母個数鈸度が $\bar{X}_{0}=$ $0.4, \bar{X}_{1}=0.3, \bar{X}_{2}=0.3$ の 3 成分混合を考える。混合度 が $M=0.1 ， 0.5 お よ ひ ゙ 1.0 の$ 場合の相対標準誤差をサン プル数 $k$ に対して，两对数グラフに示したのがFig. 2 である。実線はEqs. (35)および (38) から求めた理論 值であり，記号メはシミュレーション值である。理論 值とシミュレーション值がよく一致しており, 理論式 の妥当性を示している。また, 混合度が高くなるほど 相対標準誤差が減少し推定精度がよくなっていること がわかる。

総配位数を $n^{*}=4$ とし, サンプル数 $k=5$ の 3 成分混 合について, 混合の進行にともなって相対標準誤差が どのように変化するかを検討する。母個数渺度が異な る3つの場合(1)〜 (3) について, 混合度に对する相对 標準誤差を示したのがFig. 3である。各線はEqs. （35）および(38)から求めた理論值であり, 各記号はシ ミュレーション值である。これより,どの場合も混合 の進行にともなって相対標準誤差は単調に減少し, 推 定精度がよくなっていくことがわかる。また, 指定粒 子の母個数湌度に着目すると, 母個数濃度 $\bar{X}_{0}$ が小さい ほど，相対標準誤差が小さく推定精度がよいことがわ

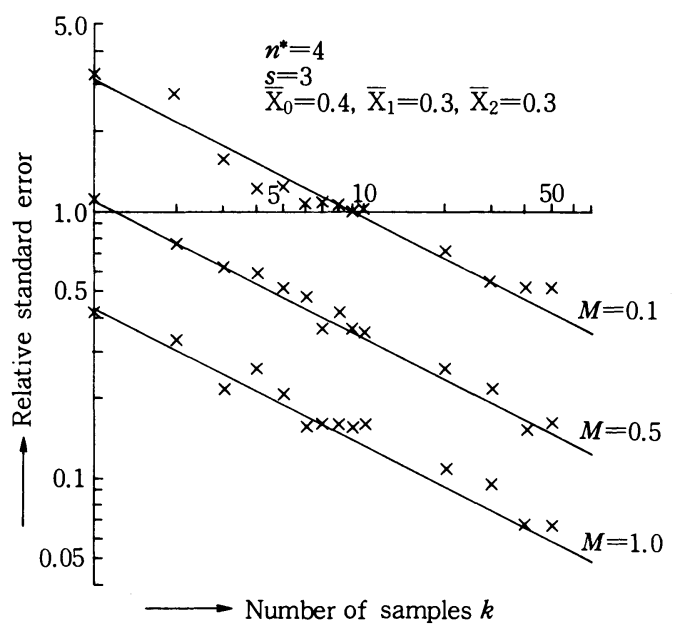

Fig. 2 Comparison of theoretical relative standard errors with those of numerical experiments in $\log$-log scale : $N=100$ 


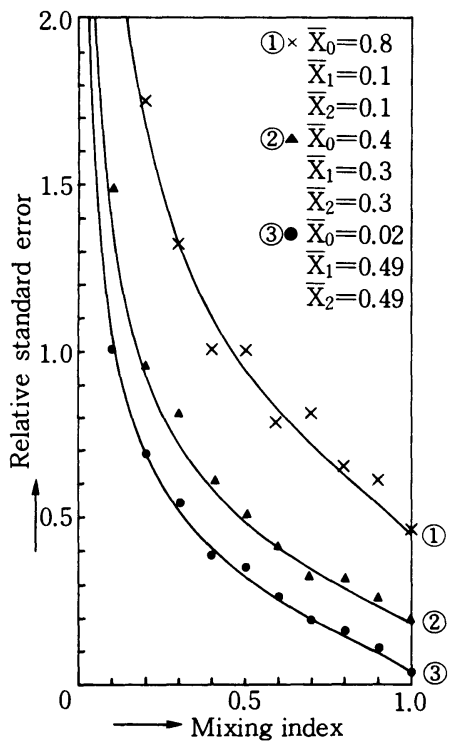

Fig. 3 Relative standard errors of the contact numbers : $n^{*}=4, s=3$ and $k=5$

かる。

次に，多成分混合を 2 成分混合とみなしたときの推 定精度を検討する。総配位数が $n^{*}=4$, 混合度が $M=0.5$ で各母個数浱度 0.5 の 3 成分混合の場合を考える。これを指定成分粒 子(母個数浱度 $\left.\bar{X}_{0}\right)$ とそれ以外の成分粒子(母個数浱度 $\left.\bar{X}_{1}{ }^{\prime}\left(=\bar{X}_{1}+\bar{X}_{2}\right)\right)$ の 2 成分混合とみなした場合および指 定成分粒子 (母個数㴤度 $\left.\bar{X}_{1}{ }^{\prime}\left(=\bar{X}_{0}+\bar{X}_{1}\right)\right)$ とその他の成 分粒子(母個数濃度 $\bar{X}_{2}$ )の 2 成分混合とみなした場合に ついて, 相対標準誤差をサンプル数 $k$ に対して両对数 グラフに示したのがFig. 4である。3成分混合の場合 (1)と, 指定成分粒子とそれ以外の成分からなる 2 成分 混合とみなした場合(2)は理論值が同じ值である。ま た，指定成分粒子の母個数筤度が $\bar{X}_{0}+\bar{X}_{1}$ の 2 成分混合 とみなした場合(3の理論値はこれらより大きくなる。 さらに，指定成分粒子の母個数浱度が同じであれば, 相对標準誤差は同じ值をとることがわかる。すなわ ち，指定成分粒子以外の粒子は推定精度には影響を与 えず，その他の粒子としてひとまとめにして考えても よいことがわかる。このことは, Eqs. (35)および(38) の妥当性を示しているということができる。

さらに，多成分混合を 2 成分混合とみなした場合， 混合の進行にともなって相对標準誤差がどのように変 化するかを検討する。総配位数を $n^{*}=4$, サンプル数 を $k=5$ とし，各母個数浱度 $\bar{X}_{0}=0.1, \bar{X}_{1}=0.4, \bar{X}_{2}=0.5$ の場合について, 3 成分混合の場合と, それを 2 成分

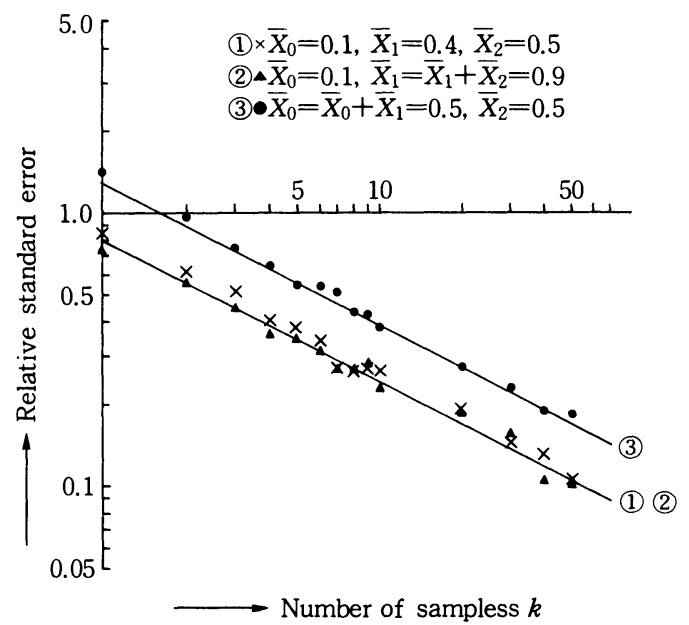

Fig. 4 Comparison of theoretical relative standard errors with those of numerical experiments in $\log$ - $\log$ scale : $n^{*}=4, s=3, M=0.5$ and $N=100$

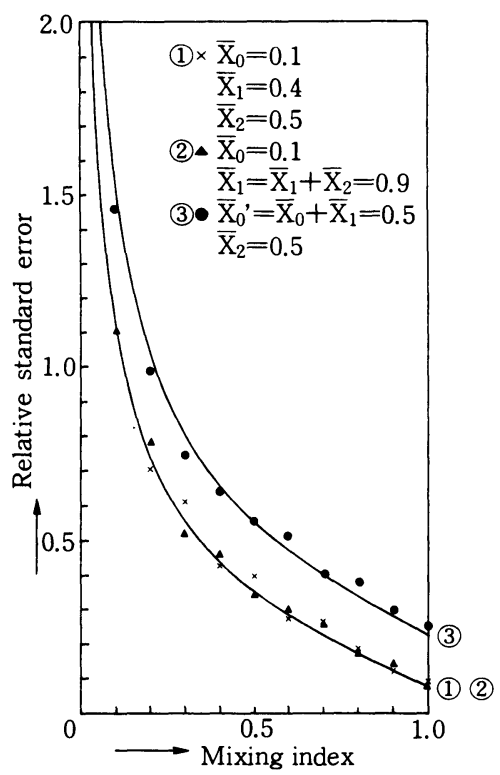

Fig. 5 Relative standard errors of the contact numbers $: n^{*}=4, s=3$ and $k=5$

混合とみなした場合の混合度に対する相対標準誤差を 示したのがFig. 5である。(1)〜3)の值についてはFig. 4 と同じ值である。これより多成分混合を 2 成分混合 とみなした場合でも, 混合の進行にともなって相対標 準誤差は単調減少し, 推定精度がよくなっていくこと がわかる。また, Fig. 4と同様に, Fig. 5においても (1)および(2)の相対標準誤差は同じ值であり，推定精度 は指定成分粒子の母個数濃度にのみ依存し，指定成分 粒子以外の母個数濃度によらないことがわかる。 


\section{5. サンプリングの設計}

通常, サンプリングを設計する場合, 各母個数湌度 は供給時に与えられるので既知とする。また, 配位数 サンプルの大きさ $n^{*}$ は混合物の構造により決まるか ら, 結局, 指定した相対標準誤差 $R S E(\widehat{M})$ を満たすサ ンプル数 $k$ を求めればよい。そこで, Eqs. (35) と (38) を $k$ について解くとそれぞれ次式のようになる。

$$
k=\frac{(\tau+1)\left(\tau+1+n^{*}\right)}{\{R S E(\widehat{M})\}^{2} \tau(\tau+2) n^{*}\left(1-\bar{X}_{0}\right)}\left\{1-\frac{\tau}{\tau+1}\left(1-\bar{X}_{0}\right)\right\}
$$

$$
k=\frac{\bar{X}_{0}}{\{R S E(\widehat{M})\}^{2} n^{*}\left(1-\bar{X}_{0}\right)}
$$

いま, 総配位数 $n^{*}=4$, 粒子の種類 $s+1=3$ として母 個数渡度 $\bar{X}_{0}=0.5$ の混合物について, 混合度が $M=0.5$ の場合それを相对標準誤差10\%で推定するのに必要と なるサンプル数を求める。そのために, 混合度 $M$ から $\tau=M /(1-M)=1$ を求めてEq. (43)に代入することに より $k=150$ を得る。また, 完全混合状態を推定する場 合には, Eq. (44) から $k=25$ 得る。このようにして求 めた結果をTable 1に示す。母個数浱度が低いほど, また完全混合状態に近いほど必要なサンプル数が少な
Table 1 Examples of the sampling designs : the number of samples required to assure the relative standard error is less than $10 \%$ : $n^{*}=4, s=3$

\begin{tabular}{c|c|c|c}
\hline & $M=0.1$ & $M=0.5$ & $M=1.0$ \\
\hline $\bar{X}_{0}=0.1$ & 612 & 62 & 3 \\
\hline $\bar{X}_{0}=0.5$ & 1150 & 150 & 25 \\
\hline $\bar{X}_{0}=0.9$ & 5993 & 950 & 225 \\
\hline
\end{tabular}

くてよいことがわかる。

\section{6. 結 言}

本報告では，新藤5)の 2 成分混合における不完全混 合状態の接触数の分布式を拡張し，多成分混合におけ る不完全混合状態の接触数の理論分布式を導出した。 また,このモデルのもとで接触数の推定精度について 検討し，コンピュータ・シミュレーションによってそ の妥当性を示した。また，接触数混合度の推定精度 は, 指定成分粒子の母個数浱度が低いほどよく, しか も，残りの他の成分粒子の母個数漕度には影響され ず，指定成分粒子の母個数浱度にのみ依存することを 報告した。

\section{Nomenclature}

$A_{\mathrm{j}} \quad:$ the $\mathrm{j}$-th kinds of particles( $\mathrm{j}=0$ to $\left.\mathrm{n}\right)$ $C_{\mathrm{j}(0),} c_{\mathrm{j}(0)}$ : random variable denoting the contact number with specified particles $A_{0}$ and its realized value

$\hat{g}_{(0)} \quad$ : estimate of the contact number of component $A_{\mathrm{j}}$

$\operatorname{Cov}($,$) : covariance operator$

$E \quad$ : expectation operator

$k \quad$ : number of samples

$M, \widehat{M} \quad$ : mixing index and its estimator

$\overline{\widehat{M}} \quad$ : mean of the $N$ estimates

$p_{j} \quad$ : local concentration of $\mathrm{j}$-th component
$R S E(\cdot)$ : relative standard error of $(\cdot) \quad(-)$

$s \quad$ : number of kinds of particles $\quad(-)$

$V \quad$ : variance operator $\quad(-)$

$\bar{X}_{\mathrm{j}} \quad$ : population concentration of $A_{\mathrm{j}} \quad(-)$

$Y_{\mathrm{j}}, y_{\mathrm{j}} \quad:$ the $\mathrm{j}$-th random variable denoting the number of particles within a coordination number sample and its realized value $(-)$ : gamma function (-) : a positive parameter (-)

: mean and variance of the contact number in the completely segregated state (-) $\mu_{\mathrm{r} j}, \sigma_{\mathrm{r} j}{ }^{2}$ : mean and variance of the contact number in the completely mixed state (-) $\mu_{\mathrm{j}}, \sigma_{\mathrm{j}}{ }^{2} \quad:$ mean and variance of the contact number in an incompletely mixed state $(-)$

\section{References}

1) Lacey, P. M. C. : J. Appl. Chem., 4, 257(1954)

2) Akao, Y., H. Kunisawa, L. T. Fan, F. S. Lai and R. H. Wang :J. Soc. Powder Technol. Japan, 15, 267(1976)

3) Yoshizawa, T. and H. Shindo : Journal. of the Jpn. Soc. for Quality Control, 7, 3(1977)

4) Fan, L. T., J. R. Too, F. S. Lai and Y. Akao:
Powder Technol., 22, 205 \& 23, 99(1979)

5) Shindo, H. : J. Soc. Powder Technol. Japan, 24, 521(1987)

6) Johnson, N. L. and S. Kotz: "Distributions in Statistics : Discrete Distributions”, Houghton Mifflin Boston, (1969) 